\title{
Development of sanitary-protection zones and sanitation gaps for the kuibyshev railway within the boundaries of settlements
}

\author{
Svetlana Teplykh ${ }^{1, *}$, Pavel Gorshkalev ${ }^{1}$, Mikhail Chernosvitov ${ }^{1}$ \\ ${ }^{1}$ Samara State Technical University, Molodogvardeyskaya St., 194, Samara, 443001, Russia
}

\begin{abstract}
Nowadays it is quite relevant to work on projects development and projects coordination of sanitary protection zones (SPZ) and sanitation gaps (SG). It is explained by mutual proximity of objects of regulation and objects of the Kuybyshev railroad within the boundaries of settlements in a dense residential development. The aim of this work is to attract attention of project organizations and design contractors to the minimum limitations of SPZ and SG (according to existing standards and regulations) as far as the factor of noise is concerned. This factor has the most tangible impact for the population. Meanwhile, there is no express reference in these documents to the cases of exceeding maximum permissible levels of noise (MPL) and to the cases of SPZ and SG crossings by several enterprises. The paper shows the results of mathematical calculations of the spread of noise from railway with and without noise screens on different test sites. The authors come to the conclusion that the existing regulations do not provide clear guidance in cases where there is an excess of physical factors of influence on the air (noise, etc.), taking into account the background, or crossings of SPZ borders and SG by several groups of enterprises. Therefore, the question whether standardized territory, (housing in particular) lies within the boundaries of SPZ (SG) of the railway or this territory is within the object of regulation boundaries is settled by court of law.
\end{abstract}

\section{Introduction}

Health care is a concern not only for doctors and ecologists, but also for designers. That is why sanitary protection zones and sanitation gaps are arranged to protect people from harmful effects of enterprises. Nowadays it is quite relevant to work on projects development and projects coordination of sanitary protection zones (SPZ) and sanitation gaps (SG). It is explained by mutual proximity of objects of regulation (first of all, residential areas) and objects of the Kuybyshev railroad within the boundaries of settlements in a dense residential development. The objects of regulation here are residential buildings. Tenants there address their complaints about increased noise from passing trains and from works done on platforms to City Administrations, Federal Service

\footnotetext{
*Corresponding author:kafvv@mail.ru
} 
for Surveillance on Consumer Rights Protection and Human Well-being and the Center for Hygiene and Public Health. In addition to the territory of residential area, to objects of regulation we refer landscape-recreation areas, recreation areas, resorts, sanatoriums, rest homes, stationary medical institutions, horticultural co-operatives and cottage developments, collective or individual holiday and horticultural patches. The aim of this study is to examine aspects of development and coordination of SPZ and SG for the Kuibyshev railway within the boundaries of settlements in a dense residential development. To achieve the aim, we have to accomplish the following objectives: to review existing regulations in the sphere of SPZ (SG) and to compare their requirements with mathematical calculations of physical effects on air (noise) from the objects of the railroad, to compare these results with MPL (maximum permissible levels of noise).

\section{Materials and Methods}

To determine physical impact distribution on atmospheric air (noise) from the transport stream the authors used a program "Ecologist-noise" together with the calculation of noise from traffic (based on the method of calculation of the noise of the traffic lines developed in the Institute of LENNIIPROEKT). The program implements the existing SNiP 3/23/2003 (Po 51.13330.2011), GOST 31295.2-2005.

SPZ and SG design is regulated by Sanpin 2.2.1/2.1.1.1200-03 "Sanitary protection zones and sanitary classification of enterprises, structures and other facilities [1]". It gives hazard rating for industrial objects and enterprises, sets out requirements for sanitary protection zones, grounds for revising those sizes, methods and procedures for laying down requirements for certain specific industrial objects and enterprises or their complexes, specifies their use and redevelopment as well as control of dangerous lines disruptions (road, railway, aviation, pipeline, etc.). For rail transport lines Article 2.6 of Sanpin [1] sets a certain distance for the source of chemical, biological and/or physical impact in order to reduce these impacts to hygienic standards. The magnitude of the gap is set separately in every particular case. Its amount is based on the calculations of dispersion of atmospheric air pollution and physical factors (noise, vibrations, electromagnetic fields, etc.), followed by field studies and measurements.

For railway stations and juncitions the most significant here is air pollution and toxicants accumulation in soils and organic soils [2]. For railroads the determining factor is noise impact.

Human response to noise depends on what processes predominate in the central nervous system: activation or retardation. Many audio signals coming into the cortex of cerebrum cause anxiety, fear, premature fatigue. In turn, this can adversely affect health. The range of influence of noise on humans is wide: from some subjective feeling to objective pathological changes in acoustic organs, central nervous system, cardiovascular, endocrine, digestive systems, etc. Therefore, noise affects vital organs and systems [3].

Other studies demonstrate the development of more severe allergic reaction of immediate type under the influence of noise than the reaction in relative silence [4], and the negative effect of noise, particularly on children's health [8].

The urgency of the problem of noise impact from rail transport operations on residential development and the need to organize sanitary protective zones is observed in Research [9]. The complexity of consolidated SPZ of several enterprises is illustrated in Paper [10].

The values of hygienic standards for the level of sound (noise) are set by SN 2.2.4 / 2.1.8.562-96 "Noise in the workplaces, in residential and public buildings and in residential areas."

Rate parameters of permanent noise are sound pressure levels L, DB in the octave bands with the following geometric average frequencies: $31.5 ; 63 ; 125 ; 250 ; 500 ; 1000 ; 2000$; 
4000; $8000 \mathrm{~Hz}$. Still, for approximate estimation it is allowed to use sound levels L (A), dBA.

Rate parameters of non-continuous noise are equivalent (for energy) sound levels LAeq, $\mathrm{dBA}$, and maximum sound levels L (Amax), dBA.

Permitted values for sound pressure levels in octave bands, equivalent and maximum noise levels within the territory of objects of regulation are given in Table 1.

Table 1. Permitted values for the territories directly ajoining homes, buildings, health centers, clinics, dispensaries, holiday homes, boarding homes, homes for the elderly and disabled, pre-school institutions, schools and other educational institutions libraries.

\begin{tabular}{|c|c|c|c|c|c|c|c|c|c|c|c|}
\hline \multirow{2}{*}{ 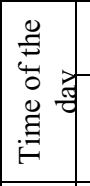 } & \multicolumn{9}{|c|}{$\begin{array}{l}\text { Sound pressure levels in octave bands }(\mathrm{dB}) \text { with } \\
\text { medium geometric frequencies }\end{array}$} & \multirow{2}{*}{$\begin{array}{l}\text { Sound levels L } \\
\text { (A) and } \\
\text { equivalent } \\
\text { sound levels L } \\
\text { (Aeq), dBA }\end{array}$} & \multirow{2}{*}{$\begin{array}{c}\text { Maximum } \\
\text { sound levels L } \\
\text { (Amax), dBA }\end{array}$} \\
\hline & $\frac{n}{m}$ & $\hat{6}$ & $\stackrel{\imath}{\simeq}$ & 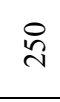 & \& & $\stackrel{8}{8}$ & 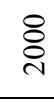 & ஓ̊ & $\bigotimes_{\infty}$ & & \\
\hline $\begin{array}{c}\dot{\Xi} \\
\dot{a} \\
\exists \\
1 \\
\dot{\Xi} \\
\tilde{\sigma} \\
r\end{array}$ & 90 & 75 & 66 & 59 & 64 & 50 & 47 & 45 & 44 & 55 & 70 \\
\hline $\begin{array}{c}\dot{a} \\
\dot{0} \\
\sim \\
1 \\
\dot{\Xi} \\
\dot{2} \\
=\end{array}$ & 83 & 67 & 57 & 49 & 44 & 40 & 37 & 35 & 33 & 45 & 60 \\
\hline
\end{tabular}

Let us remind that according to logarithmic $\mathrm{dB}$ scale, each subsequent stage of sound energy is 10 times larger than the previou; threshold of audibility is $0 \mathrm{~dB}$; conversation medium volume is $60 \mathrm{~dB}$; threshold of pain is $140 \mathrm{~dB}$ [3].

Urban noise is perceived primarily subjectively. The first indicators of its harmful influence are complaints about irritability, anxiety, insomnia. The emergence of complaints about noise and the time factor is crucial, but the degree of discomfort depends on the extent to which noise exceeds the normal level. A significant role in causing discomfort in humans is played by their attitude to the source of the noise, psychophysiological features of a certain person, as well as the noise information [3].

According to paragraph 6.8. Construction Rules and Regulation (SNiP) 2.07.01-89* "Urban Planning. Planning and construction of urban and rural settlements" [6] housing must be separated from railways of the sanitary protection zone of a width of $100 \mathrm{~m}$ from the axis of the nearest railway track. When placing the railways in the channel or on condition of special noise-reducing activities, sanitary protection zone width can be reduced, but not more than $50 \mathrm{~m}$. The distance from the marshaling yards to residential developments is based on calculation with account of the value of cargo turnover, fire and explosion hazard of transported goods, as well as acceptable levels of noise and vibration.

In the sanitary protection zone, outside the railroad right-of-way, it is allowed to construct roads, build garages, car parkings, warehouses, communal institutions. Not less than $50 \%$ of the area of sanitary protection zone should be landscaped. Landscaping not only reduces air pollution and provides a kind of noise screen, but serves for decorative purposes having a positive effect on people's mood. Width of sanitary protection zone to the borders of garden patches should be no less than $50 \mathrm{~m}$.

In the sanitary classification for industrial installations and productions (Sanpin) [1] of all railway objects only "production for road cars, vehicles, bodies, rolling stock of railway 
transport and metro repairing", hazard class-IV, are mentioned. Approximate size of sanitary protection zone here is $100 \mathrm{~m}$.

Thus, Article 2.6 of Sanpin [1] states that the size of SPZ and SG should be determined by calculations, and Snip [6] does not allow to make it less than $50 \mathrm{~m}$.

As railroad activities go on all day and night long, the width of the gap is determined by the noise during the night (sound level $45 \mathrm{dBA}$ ).

Figure 1 shows a map of the spread of noise from a kilometer stretch of railroad (with traffic frequency of 1 long-distance passenger train per hour, moving at a speed of 30 $\mathrm{km} / \mathrm{h}$ ). The calculation of noise from traffic flow is made in the module for calculation of noise from traffic, used in connection with the program "Ecologist-noise" for calculating equivalent and maximum noise levels in octave bands with geometric average frequencies of $31.5,63,125,250,500,1000,2000,4000$ and $8000 \mathrm{~Hz}$, as well as the equivalent noise level La, and is based on the methodology of calculating the noise from traffic lines developed in the Institute of LENNIIPROEKT. The calculation of noise distribution (together with a map) is made in the program "Ecologist-noise" which meets all modern requirements (Figure 1).

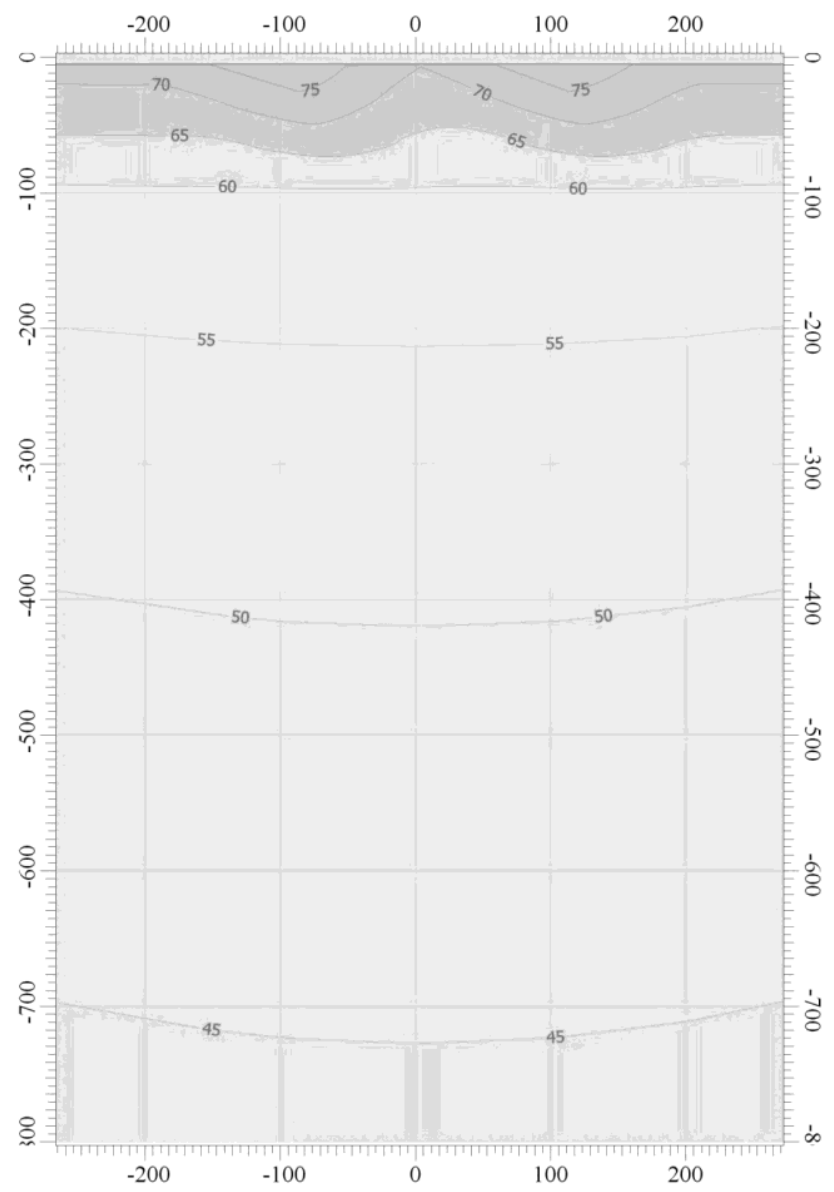

Fig. 1. Noise distribution from a railway.

Figure 1 shows that the reduction of the sound level to the required standards, even for small intensity and speed of the trains, takes over 700 meters. 
Figure 2 shows that if a 6-meter barrier (a noise screen, a building, etc) is set, an areal of incomplete closing can be observed on its boundaries. It means that extended anti-noise barries should be built on both sides of the protected object (Figure 2).

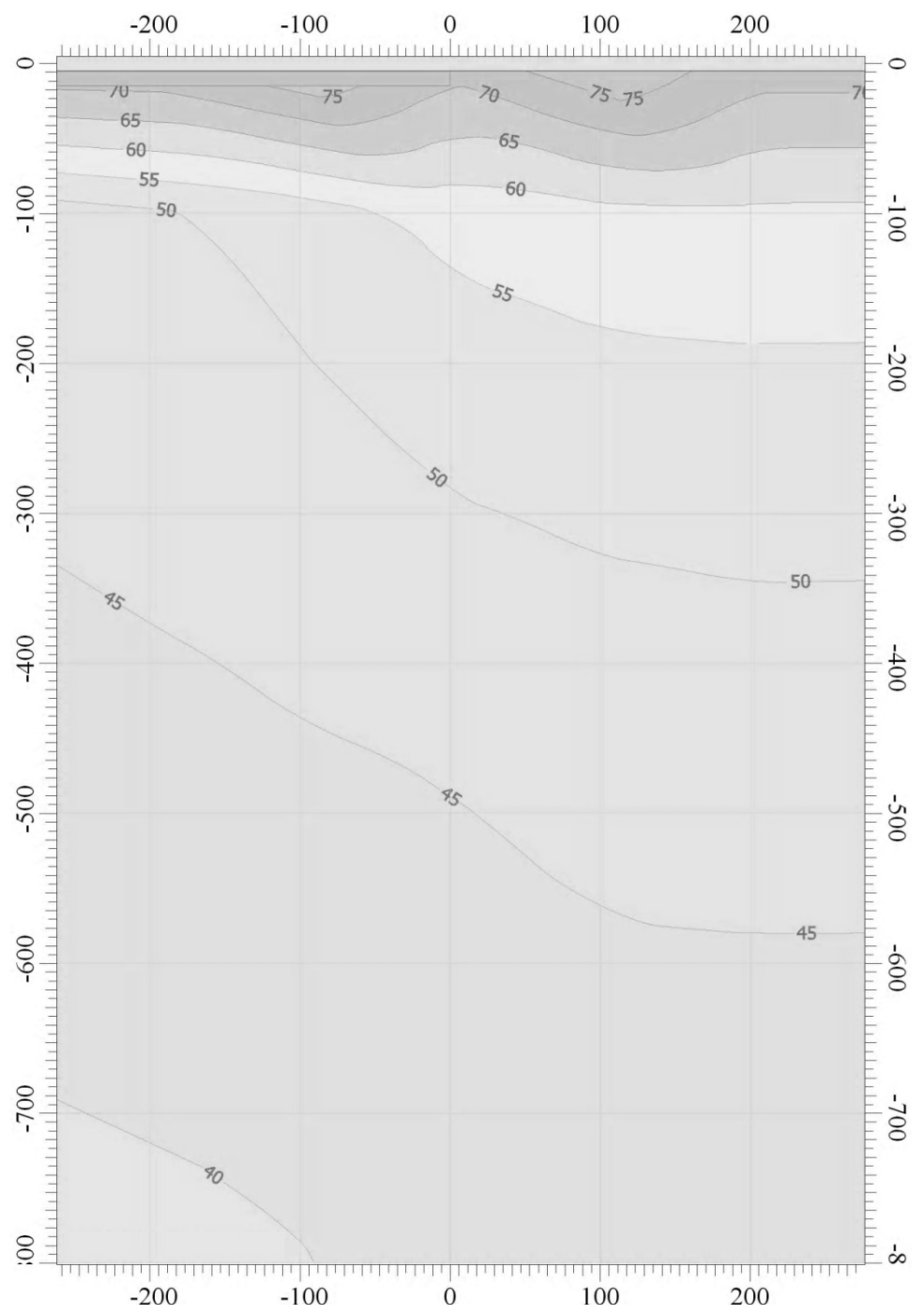

Fig. 2. Noise reduction by 6-meter barrier on its border.

In its turn, Figure 3 proves that when a 6-meter barrier is set, it is possible to reduce the sound level to acceptable values at a distance of about $50 \mathrm{~m}$. However, the following sound level calculation peculiarities should be taken into account: when we determine the level of sound, control points are located at a height of $1.5 \mathrm{~m}$ from the ground, but if there is a building in this area control points are also located at the level of the window of its upper floor (as residents of the upper floors are usually not protected by noise screens or green areas). If control points (calculated under the same conditions) are located at a height of 15 $\mathrm{m}$ (as Figure 4 shows), the width of SG should be about $100 \mathrm{~m}$ (Figures $3 \& 4$ ). 


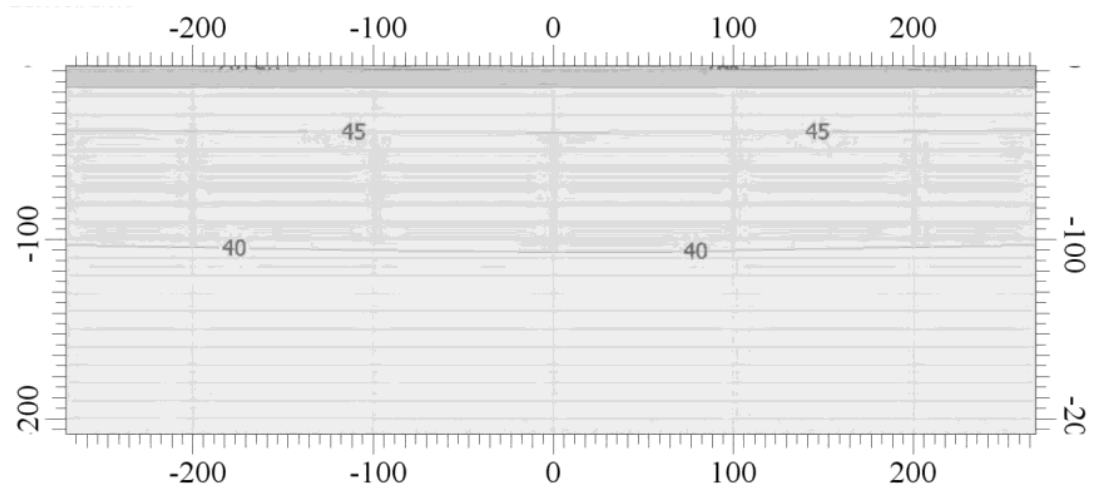

Fig. 3. Noise reduction by 6-meter barrier (test site hight is $1.5 \mathrm{~m}$ ).

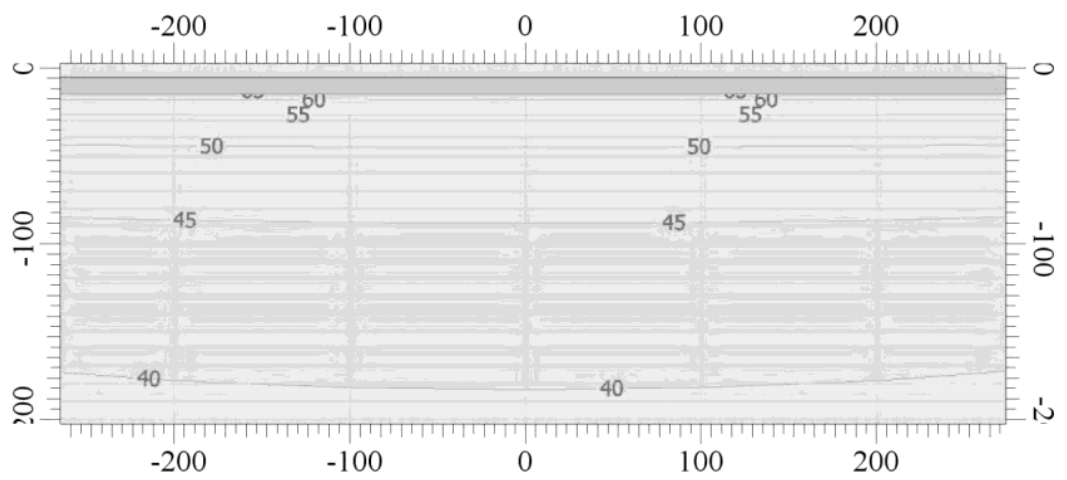

Fig. 4. Noise reduction by 6-meter barrier (test site height is $15 \mathrm{~m}$ ).

\section{Results}

Within the boundaries of dwelling settlements houses are often located at distances of less than $100 \mathrm{~m}$ and even $50 \mathrm{~m}$ from railway tracks and platforms. It is obvious that the sound levels around these houses exceed allowable limits, but here other objects, especially roads and highways, can be the source of noise for this territory. Estimated noise characteristics of roads is provided in reference literature [7], etc. For example, noise characteristics $\mathrm{L}$ (Aeq) for controlled-access highways with 4 lanes is $75 \mathrm{dBA}$ (distance from the first lane is $7.5 \mathrm{~m}$ ) as compared with $66 \mathrm{dBA}$ noise level at a distance of $25 \mathrm{~m}$ from the axis of the nearest railway track in the example above).

\section{Discussion}

Sanpin [1] requires to calculate physical factors of influence on the air (noise, etc.) with account of the background, but it gives no explanation of who is responsible for regulatory compliance on the territory where background noise exceeds existing standards. Neither explains it how the size of SPZ and SG for such enterprises should be determined.

Sanpin 2.2.1/2.1.1.1200-03 [1] states that the size of SPZ and SG should be determined by calculations, and Snip 2.07.01-89* does not allow to make it less than $50 \mathrm{~m}$.

The reduction of the sound level to the required standards, even for small intensity and speed of the trains, takes over 700 meters. A noise screen makes possible to achieve MPL 
(maximum permissible levels of noise) at distances of 50 and $100 \mathrm{~m}$ at heights 1.5 and 15 $\mathrm{m}$ respectively.

Within the boundaries of existing settlements objects of regulation are located at distances less than 50 meters from railway tracks and platforms. Thus, they penetrate into sanitation gaps (or SPZ) of other (background) objects (roads, garages, warehouses etc.). At the moment specification documents do not state who is responsible for regulatory compliance on the territory where background noise exceeds existing standards. Neither explain they how the size of SPZ and SG for such enterprises should be determined. Besides, the question whether standardized territory lies within the boundaries of SPZ (SG) of the railway or this territory is within the object of regulation boundaries is settled by court of law.

\section{Conclusions}

SPZ and SG design is regulated by SanPiN 2.2.1 / 2.1.1.1200-03 "Sanitary protection zones and sanitary classification of enterprises, structures and other facilities [1]". It states that there should be a sanitation gap for every line of railway transport. The size of SG should be determined separately for every particular case. Construction Rules and Regulation (SNiP) 2.07.01-89* "Urban Planning. Planning and construction of urban and rural settlements" instructs that the housing should be separated from railways SPZ for $100 \mathrm{~m}$ width (garden patches - not less than for $50 \mathrm{~m}$ ). SPZ may be reduced but not more than for $50 \mathrm{~m}$.

Reducing the level of noise from a kilometer stretch of railroad (with traffic frequency of 1 long-distance passenger train per hour, moving at a speed of $30 \mathrm{~km} / \mathrm{h}$ ) to the required standards is over 700 meters.

If a 6-meter barrier (a noise screen, a building, etc) is set, an areal of incomplete closing can be observed on its boundaries. It means that extended anti-noise barries should be built on both sides of the protected object.

When a 6-meter barrier is set, it is possible to reduce the sound level to acceptable values at a distance of about $50 \mathrm{~m}$ for a control point located at a height of $1.5 \mathrm{~m}$ from the ground and of about $100 \mathrm{~m}$ for a control point located at a height of $15 \mathrm{~m}$ from the ground.

Within the boundaries of dwelling settlements houses are often located at distances of less than $100 \mathrm{~m}$ and even $50 \mathrm{~m}$ from railway tracks and platforms. It is obvious that the sound levels around these houses exceed allowable limits, but here other objects, especially roads and highways, can be the source of noise for this territory.

Sanpin [1] requires to calculate physical factors of influence on the air (noise, etc.) with account of the background, but it gives no explanation of who is responsible for regulatory compliance on the territory where background noise exceeds existing standards. Neither explains it how the size of SPZ and SG for such enterprises should be determined.

All these problems and inconsistency not only complicate the work of designers and coordinators, but also prevents creating favourable ecological conditions for people living in affected areas within sanitary protection zones (SPZ) and sanitation gaps (SG).

\section{References}

1. Russian Standard SanPiN 2.2.1 / 2.1.1.1200-03 (2003)

2. A.F. Nadein, S.N. Tarhanov, O.A.Lobanov, Human Ecology 11, 14-16 (2007)

3. E.I. Goncharuk, V.G. Bards , S.I. Garkavi, O.P. Yavorovsky, Grounds Care (Health, 2006)

4. O.A. Lycheva, R.S. Galiev, Human Ecology 4, 11-15 (2012) 
5. Russian Standard SN 2.2.4/2.1.8.562-96 (1996)

6. Russian Standard SNiP 2.07.01-89* (1989)

7. G.L. Osipov, V.E. Korobkov, A.A. Klimukhin, Protection against noise in urban planning: A desiners' guide (Stroyizdat, Moscow, 1993)

8. A.P. Kharlamov, S.I. Savelyev, Public health and environment 12, 14-16 (2012)

9. Yu.N. Kaskov, Public health and environment 12, 27-28 (2013)

10. G.M. Batrakova, N.Yu. Karpov, Vestnik PNIPU 4, 76-83 (2013)

11. A. Strelkov, S. Teplykh, S Stepanov, A. Sargsyan, Procedia Environmental Sciences 32, 147-154 (2016)

12. S. Teplykh, A. Sargsyan, Regional Conference on Wastewater Purification and Reuse (IWA, 2012)

13. P.A. Gorshkalev, S.Yu. Teplykh, Surface run-off from railway tracks: complex system of calculating qualitative and quantitative characteristics $(\mathrm{GmbH} \& \mathrm{Co} . \mathrm{KG}$, Saarbrucken, 2011)

14. S.Yu. Teplykh, Water Environment 1, 140-141 (2011)

15. A.K. Strelkov, S.Yu. Teplykh, P.A. Gorshkalev, Urban Construction and Architecture 1 (9), 61-68 (2013) DOI 10.17673/Vestnik.2013.01.10

16. A.K. Strelkov, S.Yu. Teplykh, P.A. Gorshkalev, A.M. Sargsyan, Urban Construction and Architecture 4, 83-88 (2013) DOI 10.17673/Vestnik.2013.S4.23

17. A.K. Strelkov, S.Yu. Teplykh, P.A. Gorshkalev, A.M. Sargsyan, Scientific survey 4, 123-129 (2014)

18. A.K. Strelkov, S.Yu. Teplykh, A.M. Sargsyan, Geoecology 1, 88-91 (2014)

19. A.K. Strelkov, S.Yu. Teplykh, P.A. Gorshkalev, A.M. Sargsyan, Water treatment technologies 1, 181-184 (2014)

20. S.Yu. Teplykh, N.S. Bukhman, A.M. Sargsyan, Scientific survey 9, 802-808 (2014)

21. A.K. Strelkov, S.Yu. Teplykh, N.S. Bukhman, A.M. Sargsyan, Water delivery and sanitary engineering 12, 10-13 (2015)

22. A.K. Strelkov, S.Yu. Teplykh, Improvement of water systems of industrial enterprises 1, 45 (2016) 